\title{
Visibility of Work: How Digitalization Changes the Workplace
}

\author{
Hanna Timonen \\ Aalto University \\ hanna.timonen@aalto.fi
}

\author{
Johanna Vuori \\ Haaga-Helia University of Applied Sciences \\ johanna.vuori@haaga-helia.fi
}

\begin{abstract}
Digitalization is rapidly reshaping our workplaces, as digital technologies often change individual's work and collective work practices in significant but unpredictable ways. In this paper, we look at how digitalization changes the nature of work regarding work visibility, and examine this in the context of business-to-business (B2B) sales work. We report on a single case study using a practice approach to examine $B 2 B$ sales work in a small SaaS company. Our findings show how the visibility of $B 2 B$ sales work changes due to digitalization, increasing the visibility of work in relation to co-workers while decreasing it in relation to customers. Based on these findings, we discuss the complex tradeoffs in making work visible to different audiences and the gradual and constructed nature of work visibility.
\end{abstract}

\section{Introduction}

Digitalization, meaning the infusion of digital capabilities into nearly all facets of work [50], is rapidly reshaping not only markets and industries, but also the workplace. Thinkers in both the academia and the private sector believe that the speed of the current technological changes and the scale at which they could disrupt the world of work are largely without precedent [6, 33, 44]. Digital technologies are predicted to increase the automation of different work tasks, resulting in job destruction, or in turn, the creation of completely new jobs that were previously unimaginable. To keep up with these changes, companies are required to become more flexible, more fluid [39], and ambidextrous [35]. As a result, on an organizational level we have seen the rise of several virtual and nonhierarchical forms of organizing [15, $22,31]$. However, in order to fully take advantage of the potential offered by digitalization, companies need to understand how the nature of work itself is changing; digital technologies often change individual's work and collective work practices in significant but unpredictable ways $[1,11]$.

Extant research on the effects of digitalization on work has explored, for example, how interruptions due to technology affect worker focus $[9,36]$ or how technology affects task fragmentation [18, 32]. Here, we focus on how digitalization impacts work visibility. Most work conducted in knowledge-intensive organizations has traditionally been invisible: workers sit at their computers analyzing data, writing reports, or conducting other tasks that are difficult for others to discern [43]. The introduction of digital technologies and tools is now quickly changing this, and recent studies have shown how the visibility of several aspects of work are increasing [4, 7, 24, 25, 30, 37]. However, we are still lacking a comprehensive understanding about work visibility. Instead of focusing on visibility of specific aspects of work or specific work tasks, we need to understand how the nature of work changes regarding work visibility.

In this paper, we explore how the introduction of new digital technologies into the workplace can reconfigure the visibility of work. We studied business-to-business (B2B) sales work in a small SaaS company as they adopted a new digital sales model, and we focused our analysis on how this changed work visibility in relation to both co-workers and customers. In our study, we adopt a practice approach that centers around people's everyday doings. By examining actual work practices as they take place, we illuminate how the question of work visibility is much more multifaceted than previously thought in extant literature, and we discuss its gradual and constructed nature in the light of our findings.

The paper is structured as follows. Section 2 explores existing literature on the visibility of work. Section 3 describes our methodology. Section 4 presents the case, and Section 5 outlines the findings of the case study. Section 6 discusses the insights gained, and Section 7 concludes. 


\section{Visibility of work}

Visibility is the property of being perceptible by the sense of sight. This means that visibility is situated, i.e., what we see is that which lies within our field of vision, where the boundaries of this field are shaped by the spatial and temporal properties of the here and now, and the others who are visible to us are those who share the same spatial-temporal locale [45]. However, with digital technologies, visibility is freed from these spatial-temporal properties, as the visibility of individuals, actions, and events is no longer dependent on sharing a common locale.

In this vein, digitalization has the inherent potential of making various aspects of people's work more visible to a broad organizational audience. Past studies have examined how different technologies have increased the visibility of the location where the work is conducted [27], the social presence and activity status of workers $[4,19,30]$, different work tasks [7, $30]$, and the workflows related to these work tasks [20, 37]. Also, the nascent theory of communication visibility $[24,25]$ shows how the visibility of internal workplace communication has gradually increased, starting from face-to-face encounters who are largely invisible to all but the parties involved, moving on to contemporary communication such as email or instant messaging, which are more easily shared with others, and finally to social media applications that make routine communications with co-workers instantly visible to third parties [46].

Despite this existing research on issues of visibility in relation to certain aspects of work, as in certain work tasks and work activities, we are still lacking a comprehensive understanding of work visibility and how the changes in work visibility also change the nature of the work in question. In the first place, the increase of work visibility has both its advantages and disadvantages. For example, increased visibility has been shown to enhance awareness of who knows what and whom, thus avoiding duplication of knowledge and creating more innovative products and services [24], and increase employee engagement as workers learn about the personal and professional contexts of their co-workers [38].

At the same time, visibility has also been shown to create counterproductive organizational behaviors [14]. In fact, work conducted 'backstage' [17] might be invisible for a reason. Increased visibility might undercut necessary workarounds around bureaucratic rules or disable professionals' possibilities to work from within a personal framework [42]. Thus, increasing the visibility of previously invisible work might make individuals uncomfortable, therefore inciting them to re-create possibilities to make the work invisible again [20].

Moreover, changes in the visibility of work tasks or work activities to certain audiences might prompt workers to change their workplace behavior, as the changed visibility subjects their work to substantially different interpretations by actors differently positioned, with correspondingly different interests in relation to the activities being seen [42]. For example, when employees become more aware of what they are doing and with whom, they might begin to regulate their workplace behaviors, sometimes exaggerating certain aspects of their work and other times concealing aspects of their behavior in hopes of successfully managing impressions of others [14]. It follows that in order to evaluate how changes in work visibility affect the nature of work as a whole, and to understand what tradeoffs are involved in making work visible [42], we need to contextually analyze what aspects of work digital technologies are making more or less visible and to which audiences [41]. The latter is especially true in contexts where work visibility changes in relation to inter-organizational audiences.

\section{Methodology}

We conducted a single case study [40, 49] to analyze how the adoption of new of digital technologies changed the nature of work regarding work visibility. We chose to study B2B sales work in a small SaaS company called DigiSite as they adopted a new digital sales model in their sales organization. This presented the perfect opportunity to study how B2B sales work and visibility of work was changing, as we were able to collect data both before and after the organization adapted several new digital tools. At DigiSite, sales work changed from having traditional face-to-face meetings with customers to having what we call digital meetings, which consist of phone calls combined with a screen sharing system and interactive business presentation software that is used to demo the company's digital services.

As the forms of organizing and the experiences of workers are intimately tied to what people do, how they do it, and to the social order that both shapes and is created by work [3, 34], our study followed a practice approach that centered around people's everyday doings [10]. This means that we see work as 'a doing,' constituted by both the dynamic and situated activities of workers. This view focuses on the embodied practical understandings that are entangled with material configurations at particular times and places, rather than static or abstract tasks that make up 'the work.' Our approach thus follows recent calls to 
build our understanding of work based on specific accounts of actual work practices [2], which enables us to see how individual workers successfully leverage the effects of digitalization to accomplish their work [cf. 12].

The data for this study was collected in two phases. In 2014, our research team conducted four in-depth qualitative interviews with the top management and salesforce, lasting 60 minutes on average. These interviews focused on the sales strategy and sales model used by the company at that time, to which we refer in this paper as the traditional sales model.

After the company switched to what we call a digital sales model in 2016, our research team returned to the company to collect more data. As we were now interested in understanding how the nature of the sales work was changing, we decided to collect data that would provide us detailed descriptions of the work practices of salespeople. Thus, during 2016 and 2017, we collected data through fieldwork methods. The authors observed the sales manager and the two salespeople doing digital sales for a total duration of approximately 36 hours over 14 days, taking detailed notes of their work and conducting several informal face-to-face discussions with them. During this time, the authors and other members of the research team also video recorded 17 digital sales meetings as they took place. These digital meetings were held by three different salespersons, covered 11 separate customers, and their duration varied between 12 minutes and 74 minutes. With only a few exceptions, the research team also conducted short, 5- to 10-minute debriefing interviews after the sales meetings with both the salesperson and the customer, asking them to verbalize how the meeting went and how they felt about it. Finally, we conducted two in-depth interviews, one with the sales manager and another with one of the salespersons. All the videos and interview recordings were transcribed verbatim for analytical purposes.

Our data analysis followed an iterative process of inductive coding, largely based on the systematic, yet flexible guidelines of grounded theory [8, 16]. Grounded theory is one of the most widely used qualitative research methods across a wide range of disciplines and subjects [5, 29]. It is also becoming more prevalent in both sales research $[13,21]$ and IS research $[47,48]$.

The data analysis followed two general analytical principles of grounded theory. First, we followed the constant comparative method, which is a "procedure in which two activities, naming data fragments and comparing data incidents and names, occur in tandem" $[28$, p. 25]. With constant comparison, all new data are compared to earlier data iteratively to enable adjustment of theoretical categories based on the ongoing analysis. Second, we followed the principle of emergence that states that the developed explanations must fit the data under study, and it must meaningfully explain the behavior under study [16].

\section{Case: The development of a new digital sales model at DigiSite}

DigiSite is a small software company offering digital SaaS services such as time tracking, task management, worksite diaries, and automatic reporting mainly for the construction industry. Based in Finland, the company has approximately 1,500 customers in Finland and Sweden, and aims to digitalize every construction site in Europe with its software and mobile solutions. Because of the scalability of their offering, their customer base ranges from very small construction companies to major industry players. The company estimates to have a $35-40 \%$ market share in Finland.

DigiSite started to sell their services using a SaaS model in 2009. At that time, they continued to embrace the same traditional sales model they had already been using when selling their software using a license model. In this model, the company had a number of traditional salesmen who were complemented with a small number of online support personnel at the office. The salesmen worked mainly out in the field doing direct sales with prospective customers. They were not employed by the company, but rather acted as subcontractors, i.e., they sold DigiSite's services on their own account and were paid based on results. The salesmen searched for new leads by contacting their present customers and asking for references of other companies who might be willing to switch to digital construction site management. Robert, the sales director at that time, estimated that every second sales meeting call by the field sales force led to results. The key to success in this model, according to both the salesmen and management, was the salesmen's ability to speak in prospective customer's language and their skills in seeing construction site management through the customers' eyes.

In 2015, Robert was promoted to CEO of the company. Despite the apparent success of the old model, Robert started to shift DigiSite's sales strategy to lean on the digital. For this purpose, he recruited a new sales director, Mark, in 2016. Mark had previous experience in digital business, so Robert thought he would be a perfect fit to build a new 'digital salesforce' for the company. Characterizing the field salesmen as 'horsemen' or 'notebook men,' Mark wanted to build his new digital sales model by recruiting and training new salespeople. He strived to replace the old 
notebook with a new, digital and cloud-based CRM system, and have the salespeople use their time efficiently by sitting in the office and interacting with the customer using digital channels.

Mark started to build his new digital sales concept by actually doing the work himself, booking sales meetings with new customers. He decided to complement traditional telephone calls with a screen sharing tool that enables simultaneous demonstration of the company's digital services. During 2016 and 2017, Mark developed the model further and recruited two new salespersons to focus exclusively on digital sales. By mid-2017, the new sales model was already proving to be very successful: the hit rate in digital sales was at the same level as in face-to-face sales, but the new model had resulted in 2.3 times more sales meetings and almost 4.5 times more sales activities per month. Between 2016 and 2017, the digital sales staff also increased their number of won deals per salesperson by over $46 \%$, and shortened their closing time by 14 days.

DigiSite's current digital sales model consists of a phone call combined with a screen sharing system and interactive business presentation software that is used to demo company's digital services. In addition, the salespeople use a digital CRM system and two digital platforms for prospecting and lead generation. The company also actively uses a digital internal team collaboration tool. In the sales model, the appointment can be made either by a booking firm or the salesperson directly. At the time of the digital meeting, DigiSite's salesperson calls the customer by phone and asks them to open the screen sharing connection via a link sent to them beforehand through e-mail. The typical setup of the meeting from a salesperson's point of view can be seen in Figure 1.

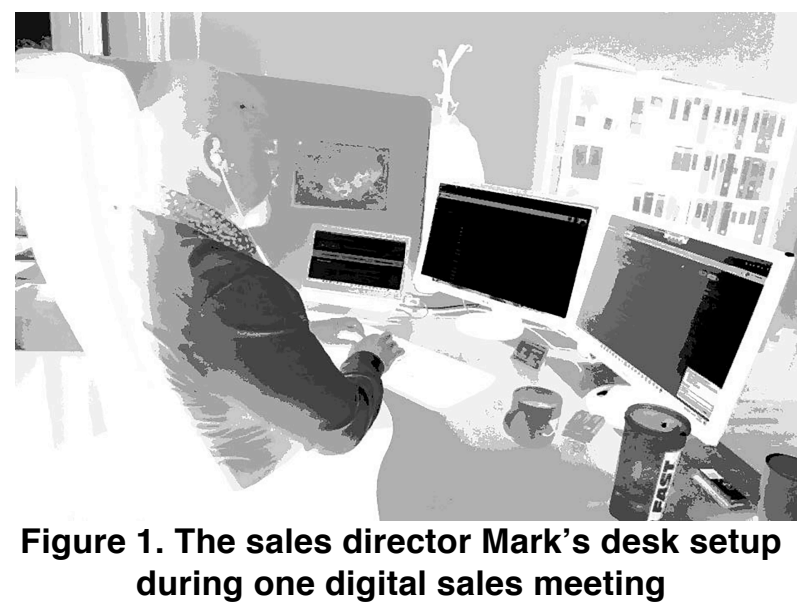

A sales meeting with a prospective customer starts by the salesman asking the customer to describe their business. The salesperson then succinctly presents DigiSite by showing slides through the screen share. Based on the hints he has collected about the customer's main concerns and interests, the salesperson continues the presentation by demoing the digital services by pointing out how their solutions might help the customer with construction site management. Either during this or a subsequent meeting, the salesperson also sets up a trial service for the customer that is customized to fit the customer's business needs. If there is enough time and the trial service can easily be set up during the meeting, the customer may even get to use the trial service guided by the salesperson through the screen sharing system.

\section{Findings}

In general, the nature of sales work at DigiSite changed in many ways due to the adoption of the digital sales model. For example, the salespeople were now required to multitask during the sales meetings: they were writing notes on the CRM tool while simultaneously listening the customer, preparing the slide presentations, and solving connection problems. The nature of sales work also became more complex and oriented toward problem-solving, which also seemed to add to sales work's cognitive load. Moreover, as the digital sales meetings also changed how customers dealt with meetings and how the meetings were scheduled, salespeople needed to develop new work practices in order to better manage their personal work time and schedules.

In the following, we present our findings on how the digital sales meetings changed work visibility at DigiSite in two aspects. We first discuss how visibility changed in relation to co-workers and then how it changed in relation to customers.

\subsection{Visibility of sales work in relation to co- workers}

At DigiSite, the adoption of the new digital sales model made sales work more visible to co-workers. For one, the change from face-to-face meetings to digital meetings brought the salespeople physically back to the office, as they now held the meetings at their own desk instead of the customer's office, construction site, or even the gas station. In the small open office space, their conversations with the customers were now audible to all other co-workers sitting in the same space. The extent of this was even to a point that when several salespeople were having 
digital meetings simultaneously, they would sometimes put up improvised partitions to at least block the view of the other person.

On several occasions during our fieldwork, the sales director or other salespeople would comment on the digital meeting after it had ended. Most of these comments were encouraging and supportive, and helped the salespeople to both share experiences and knowledge and to co-create knowledge about their own work activities, the tools they were using, or even the digital services they were selling. For example, after one noticeably quite difficult digital meeting we observed with one salesman, John, his co-worker Mike started a discussion by asking "Huh, that was a difficult one, wasn't it?" This comment enabled John to not only vent his feelings after a difficult meeting but also to identify a potential problem in the spreadsheet-based pricing tool they were using. Although the salespeople seemed to mostly enjoy and benefit from this increased visibility of their work, we felt that it also increased the accountability that the salespeople experienced in relation to their co-workers, especially regarding unsuccessful meetings.

Sales work also became more visible through various kinds of new digital tools, such as electronic calendars, which were visible and open for making bookings by co-workers; an external booking company; a new digital CRM system where notes were made during and after the sales meetings; and an internal team collaboration tool used by the whole company. Also, as the new digital sales model was developed around demoing the company's digital services live to the customer, each salesperson developed their own demo service that was accessible to others. This visibility also changed the ways in which the salespeople would work during sales meetings: if something happened during the sales meeting, such as a technical issue or a question they did not know the answer to, they could reach out to their co-workers for help even without letting the customer know. As the co-workers present at the office could also hear the meeting discussions, they could even offer help directly if they noticed that something was going wrong. In Vignette 1, we see an example of this kind of a situation, where the sales director Mark cuts in and corrects what John is telling to the customer.

Vignette 1: John receives help from the sales director

John is some 30 minutes in on a meeting with a customer, demoing the car mileage log feature of the service. The customer asks if the mileage entry is first linked to a certain project. John replies that the mileage log is not linked to any specific project. He's already moving on with his explanation, when the sales director sitting across the room from him stands up and shouts, "Yes you can link the mileage log to the projects through the settings!"

Hearing the loud shout through his headphones, John looks up to the sales director and stops right in the middle of his next sentence. He immediately corrects himself to the customer: "Okay. So, my colleague just now told me that you can actually link it through the settings, to a project." The sales director gives him thumbs-up, and John matches the gesture. The sales director sits down.

John redirects his gaze to his laptop, and starts typing into the company team collaboration tool, while continuing his discussion with the customer, who rhetorically asks: "So you can add the mileage log to a small project's bookkeeping?" While exchanging some instant messages with the sales director, John agrees by saying, "Yes, it's possible. It's good that they corrected me here." and continues to tell the customer how to go on to change the settings regarding the mileage log.

As we see in Vignette 1, John is not at all distracted or annoyed by the sales director cutting in, but he even initiates a short exchange with him on the company team collaboration tool in order to provide additional information to the customer. At a later point in the same meeting, John even solicits the sales director's help again when negotiating the price of the service package with the customer.

\subsection{Visibility of sales work in relation to customers}

As we have now seen, the new digital sales model made salespeople's work more visible to their coworkers. However, simultaneously, their work became less visible to the customers. This was already illustrated in Vignette 1, where John was able to use the company's digital team collaboration tool during the sales meeting to continue communicating with the sales director, while still continuing his meeting with the customer, who was completely unaware of the parallel discussion taking place. The social norms guiding face-to-face sales meetings typically don't allow the use of these kinds of tools during traditional sales meetings. For example, it would be considered quite inappropriate for the salesperson to google the customer's company or check a digital prospecting platform for some financial information about the company during a face-to-face meeting. However, the decreased visibility of a digital meeting allows these kinds of work activities as long as they remain 
unnoticed by the customer. As a result, the salespeople are often multitasking during digital meetings: they need to keep the connection and the discussion going on with the customer, and even listen very carefully to what they say, while simultaneously taking care of the flow of the meeting and making sure it stays on schedule, using the demo service, managing what shows on the shared screen using various digital tools, writing notes in the digital CRM system, checking information or making calculations related to making customized offers, communicating with co-workers, and so on.

There are also other norms guiding face-to-face meetings that tend to lose their meaning in the context of digital meetings. Especially in the case of DigiSite, where the salespeople are not having a video call with the customer, their external habitus and behavior remain invisible to the customer, giving them a lot more freedom in how they can dress and what they can do during the meetings. For some of the salespeople in our study, this meant that they could move and behave quite strangely, engaging in various kinds of auxiliary activities like dismantling ballpoint pens, folding paper cups, or just rolling around with their office chairs. We might even presume that these bodily activities help the salespeople to cognitively keep their focus better on the conversation they are having with the customer. In our interviews, the salespeople also said that the absence of video helped them to mask their nervousness better.

While the decreased visibility in relation to the customer might enable the salespeople to work in new ways and not care about their appearances while working, it also means that the environment in which the salespeople are having these meetings is equally invisible to the customer. As a result, the salespeople also sometimes needed to block this environment out from their attention field in order to really focus on their conversation with the customer. In Vignette 2, we see a situation where the distractions from the surroundings made the meeting even more taxing.

Vignette2: dealing with distractions without the customer noticing

This is the third consecutive digital meeting with the same customer on this very same day. Twice already Mark had promised to the customer that they could continue at a later time, as he needed to take care of more urgent things. It is now evening and everyone else has left the office.

Finally, the third meeting starts. Forty-five minutes into the meeting, the janitor enters the office and starts vacuuming. Little by little he gets closer to Mark's desk. At first, Mark does not seem to even notice him, and continues to explain the features of the demo service. The janitor approaches and starts vacuuming the rug in front of Mark's desk. He moves a chair on the opposite side of Mark's desk to be able to vacuum the floor under it. Mark continues to speak with the customer, but for a brief moment he raises his hand and greets the janitor. The janitor moves even closer, to Mark's side of the desk, and vacuums the floor around his office chair. Mark keeps his calm and just keeps on talking with the customer.

While describing the level of skills and stamina that keeping one's focus on the customer might require, Vignette 2 simultaneously shows one of the reasons why these qualities are so much more important in the context of digital sales meetings: the salespeople need to work much more to get the customers to commit to the meeting and eventually to the next step in the sales process.

Getting customers to commit and actively participate in digital meetings also required the salespeople to change their interaction practices during the digital meetings. As in face-to-face meetings, the salespeople are expected to be 'in charge' of sales meetings, taking the agenda forward. As digital meetings with a shared computer screen do not provide the participants access to other nonverbal cues despite the voice, the salespeople need to actively create space for the customers to speak during the digital meetings; otherwise, the salespeople might not have any cues that would tell them if the meeting is going well or not. Particularly difficult moments in digital sales meetings are when customers are silent as then the salesperson has no clue whether they have lost them completely, bored them, or puzzled them. On these occasions, the salespeople might resort to 'status checking,' especially during those parts of the meeting when the salesperson was talking more, for example the company presentation.

In addition, the salespeople must verbalize the actions they are doing on screen. This not only makes salespeople's online actions easier to follow on the screen for the customer, but also often provides additional information on the intent behind these actions. An example of this verbalization as a means to increase visibility is seen in Vignette 3.

\footnotetext{
Vignette 3: making actions visible through verbalization

Mark has three computer screens open on his desk. He tells the customer that he will give a short presentation on DigiSite before they move on to the service demo. Mark transfers content from one screen to the shared screen, verbalizing his action to the customer through "I will just locate this." The
} 
customer asks him to use his own words instead of reading out load, to which Mark laughs.

Mark continues: "Now you should see a sort of a screen." The customer first replies, "Yes, it starts now, at least something happened," but a moment later he says that he is only able to see half of the screen. Mark starts transferring content from one screen to another again and says: "No problem, I can do his. Here, let's do it this way and let's see." They pause for a while. After, Mark continues to move contents in-between the three screens and speaks aloud. "Wait, I'll just see what does it say about this. How about now?" To this the customer finally replies: "Well, now I can see, yes."

Based on our observations and our discussions with the salespeople, the increased need to verbalize things also resulted in changes in the selling style that the salespeople adopted in digital meetings. For example, salespeople needed to develop new kinds of practices to 'check the status' of the customer without being too blunt and to lower the bar for the customer to interrupt them and ask questions. As a result, the salespeople found themselves often taking more of a guiding role in the digital meetings, especially when demoing the service. Salespeople themselves described the new style as more 'consultative,' but it can also be seen as adopting features from communication that takes place in pedagogical and/or coaching settings.

\section{Discussion}

Based on the findings of our study, the question of work visibility seems to be much more complex and multifaceted than considered by previous literature. Our findings show how the adoption of new digital tools in the context of B2B sales work did increase work visibility in relation to co-workers, but also decreased work visibility it in relation to the customer. Digitalization increased the visibility of B2B sales work in a similar way to what has been noted in previous studies $[25,46]$. However, this increase took place when looking at the visibility of work within the organization, that is to intra-organizational audiences, whereas the visibility of work decreased in relation to inter-organizational audiences. Thus, work conducted at organizational boundaries seems to inherently have some aspects of the work visible to one side and invisible to the other.

As a result, the adoption of new digital tools does not always mean that the visibility of work increases towards all audiences. Instead, it seems that there are complex tradeoffs in making work visible to different audiences [see 42], especially in inter-organizational settings. In our study, the salespeople felt that the digital meetings were more compact, effective, and permitted less unnecessary chit-chat. In exchange, they provided less opportunities for rapport-building with the customer, an essential requirement in building trust necessary for bigger sales cases.

\subsection{Theoretical implications}

Our findings increase the current understanding of work visibility by highlighting both its gradual and constructed nature. In the first place, our findings show that work is never visible to others in its entirety. In fact, the visibility of work increases or decreases gradually, depending also on what kind of work activities are made more or less visible, and to what audiences. So, visibility is not a black-and-white, onor-off kind of phenomenon, where the work would clearly be either visible or invisible to others. Increasing the visibility of work in some aspects or to some audiences can hold the tradeoff of simultaneously decreasing it in other ways.

Despite the changes in work visibility, the division between the 'frontstage' and the 'backstage' in sales work remained strong [17]. The sales meetings with customers, as in any service work, were clearly work that could be understood as 'frontstage.' In fact, a lot of the challenges that the salespeople faced due to changes in work visibility related to maintaining the division between 'frontstage' and 'backstage.' The salespeople took effort in keeping their 'backstage' work, such as dealing with distractions or communicating with co-workers, invisible to the customer, whereas they readily engaged in new kinds of practices such as verbalizing so that their 'frontstage' work would become more visible to the customer. However, the decreased work visibility in relation to the customer made it possible for the salespeople to simultaneously engage in the 'backstage' and the 'frontstage' through multitasking, something that they did not previously do.

Secondly, our findings show that work visibility is not a given, but something that is also actively constructed by the workers themselves. This means that work is never visible to others as such, but always as a representation, as workers actively shape how their work appears to others [42]. If workers feel uncomfortable with making certain aspects of their work visible, they can engage in self-preserving behaviors by not communicating the true nature of their work, but rather what they believe others think they do and know [26].

In the case of digital meetings at DigiSite, work became more visible for the customers through practices such as verbalizing that the salespeople 
themselves adopted. Through these kinds of work practices, the salespeople themselves managed what work tasks and work activities they decided to have on the 'frontstage' versus the 'backstage.' As another example, the salespeople were able to manage the level of their work visibility in relation to co-workers by deciding how they used the digital tools offered. As the notes made in the digital CRM system were made visible to all co-workers and thus could be used for peer evaluation, they were now being written to maximize the visibility of individual workflows in order to show the time and effort used.

\subsection{Managerial implications}

We propose that the changing nature of work visibility offers several potential benefits for B2B sales organizations. First, the reduced work visibility between the salesperson and the customer can be used to improve service quality, as the salesperson has access to additional resources during customer meetings. Information offered by digital platforms and support from co-workers may be used, for example, to provide faster and more accurate answers to unpredicted customer questions and to quickly solve technical hiccups.

Second, the increased work visibility within the sales organization creates new opportunities for organizational learning by enabling vicarious learning: in addition to learning experientially by communicating with co-workers, salespeople can also learn vicariously by watching them work. This may also contribute to more agile development of sales processes if salespeople work collectively to recombine their existing ideas into new ideas.

Third, the increased work visibility within the sales organization may also contribute positively to the sales organization by enhancing internal social relations and team building. As the salespeople are no longer working alone out in the field, they are able to share both the struggles and the successes of customer work with office colleagues who can provide not only feedback on work but also social support. However, as salespeople are typically quite competitive and sales compensation practices are often built around individual revenue targets, it might take some time and effort to build a more cohesive and supportive sales culture. However, a more collectively oriented sales culture might also attract younger, tech-savvy, and more collectively oriented people to enter the profession. Training and support for newcomers without a strong background in field sales is also easier to organize in the context of in-house digital sales and supported by the possibilities for vicarious learning.
Our findings relating to how work visibility is changing due to digitalization also have more general managerial implications. Companies need to acknowledge that as work is changing, new skills and competency requirements are not only limited to the use of technology. As shown by our study of B2B sales work, salespeople not only needed to be proficient in using the new digital tools, but they also needed to multitask (for example use several computer screens simultaneously and search for new information while speaking with the customer), develop new ways of communicating with customers (for example verbalizing), and have a problem-solving orientation (for example solve different kinds of technical errors and problems on the fly). As a result, companies need to rethink what kind of in-house training programs they need to coach the old salesforce in these new skills, and what kind of hiring criteria to use in the future.

In addition, we noticed that as work visibility changes due to digitalization, the nature of work seems to become more complex and cognitively taxing though multitasking and problem-solving activities. In digital sales, the salesperson has to have a holistic understanding not only on the adaptability of their own service to different contexts, but also of the sales process and its connection with other processes of the company and the local IT environment. Companies need to make sure they have sufficient supporting structures that help people to develop their own work practices and self-management skills in order to deal with stress in an effective manner.

\section{Conclusion}

In this paper, we have discussed how the nature of B2B sales work is changing due to digitalization. We have especially discussed work visibility. We have shown how the visibility of B2B sales work changes due to digitalization, increasing the visibility of work in relation to co-workers while decreasing it in relation to customers.

Based on our findings, we have discussed the complex tradeoffs in making work visible to different audiences. As a result, we have shown the gradual and constructed nature of work visibility; on one hand, the visibility of work increases or decreases gradually, depending also on what kind of work tasks and work activities are made more or less visible, and to what audiences, and on the other hand, the visibility is not a given, but something that is also actively constructed by the workers themselves. 


\section{References}

[1] S.R. Barley, and B.A. Bechky, "From the editors. The changing nature of work: careers, identities, and work lives in the 21 st century", Academy of Management Discoveries, 3, 2017, pp. 111-115.

[2] S.R. Barley, and G. Kunda, "Bringing work back in", Organization Science, 12, 2001,pp. 76-95.

[3] S.R. Barley, and P.S. Tolbert, "Institutionalization and structuration: studying the links between action and institution", Organization Studies, 18, 1997, pp.93-117.

[4] J. Birnholtz, G. Dixon, and J. Hancock, "Distance, ambiguity and appropriation: structures affording impression management in a collocated organization", Computers in Human Behavior, 28, 2012, pp. 1028-1035.

[5] A. Bryant, and K. Charmaz, "Introduction. Grounded Theory Research: Methods and Practices", In the SAGE Handbook of Grounded Theory, A. Bryant and K. Charmaz, eds., SAGE Publications, Thousand Oaks, CA, 2007, pp. 128 .

[6] E. Brynjolfsson, and A. McAfee. "The second machine age: work, progress, and prosperity in a time of brilliant technologies", W.W. Norton and Company, New York and London, 2014.

[7] J.M. Carroll, M.B. Rosson, U. Farooq, and L. Xiao, "Beyond being aware", Information and Organization, 19, 2009, pp. 162-185.

[8] K. Charmaz, "Constructing grounded theory: a practical guide through qualitative analysis", SAGE Publications, London, 2006.

[9] A.R. Dennis, J.A. Rennecker, and S. Hansen, "Invisible whispering: restructuring collaborative decision making with instant messaging", Decision Sciences, 41, 2010, pp. 845886.

[10] M.S. Feldman, and W.J. Orlikowski, "Theorizing practice and practicing theory", Organization Science, 22, 2011, pp. 1240-1253.

[11] C. Forman, J.L. Ling, and K. Lyytinen, "Special section introduction. Information, technology, and the changing nature of work", Information Systems Research, 25, 2014, pp. 789-795

[12] J.E. Gaskin, and T. Skousen. "Time-chunking and hyper-refocusing in a digitally-enabled workplace: six forms of knowledge workers", Frontiers in Psychology, 7, 2016, article 1627.

[13] S. Geiger, and D. Turley, "Grounded theory in sales research: an investigation of salespeople's client relationships", Journal of Business and Industrial Marketing, 18,2003 , pp. $580-594$.

[14] J.L. Gibbs, N.A. Rozaidi, and J. Eisenberg, "Overcoming the "ideology of openness": probing the affordances of social media for organizational knowledge sharing", Journal. of Computer-Mediated Communication, 19, 2013, pp. 102-120.

[15] C.B. Gibson, and J.L. Gibbs, "Unpacking the concept of virtuality: the effects of geographic dispersion, electronic dependence, dynamic structure, and national diversity on team innovation", Administration Science Quarterly, 51, 2006, pp. 451-495.

[16] B.G. Glaser, and A.L. Strauss, "The discovery of grounded theory: strategies for qualitative research", Aldine de Gruyter, New York, 1967.

[17] E. Goffman, "The presentation of self in everyday life", Doubleday Anchor, Garden City, NY, 1959.

[18] V.M. González, and G. Mark, "Constant, constant, multi-tasking craziness: managing multiple working spheres," In Proceedings of the SIGCHI Conference on Human Factors in Computing Systems, ACM Press, New York, NY, 2004, pp. 113-120.

[19] C. Heath, and P. Luff, "Technology in action", Cambridge University Press, Cambridge, UK, 2000.

[20] L.J. Holtzblatt, L.E. Damianos, and D. Weiss, "Factors impeding wiki use in the enterprise: a case study", In Proceedings of the 28th International Conference Extended Abstracts on Human Factors in Computing Systems, ACM Press, New York, 2010, pp. 4661-4676.

[21] J.S. Johnson, "Qualitative sales research: an exposition of grounded theory", Journal of Personal Selling and Sales Management, 35, 2015, pp. 262-273.

[22] W.F. Joyce, V.E. McGee, and J.W. Slocum, "Designing lateral organizations: an analysis of the benefits, costs, and enablers of nonhierarchical organizational forms", Decision Sciences, 28, 1997, pp. 1-25.

[23] P. Kinnaird, L. Dabbish, and S. Kiesler, "Workflow transparency in a microtask marketplace", In Proceedings of the 17th ACM International Conference on Supporting Group Work, ACM Press, New York, 2012, pp. 281-284.

[24] P.M. Leonardi, "Social media, knowledge sharing, and innovation: toward a theory of communication visibility", Information Systems Research, 25, 2014, pp. 796-816.

[25] P.M. Leonardi, "Ambient awareness and knowledge acquisition: using social media to learn 'who knows what' and 'who knows whom'”, MIS Quarterly, 39, 2015, pp. 747762. 
[26] P.M. Leonardi, and J.W. Treem, "Knowledge management technology as a stage for strategic selfpresentation: implications for knowledge sharing in organizations", Information and Organization, 22, 2012, pp. 37-59.

[27] P.M. Leonardi, J.W. Treem, and M.H. Jackson, "The connectivity paradox: using technology to both decrease and increase perceptions of distance in distributed work arrangements", Journal of Applied Communication Research, 38,2010 , pp. 85-105.

[28] K. Locke, "Grounded theory in management research", SAGE Publications, London, 2001.

[29] K. Locke, and S. Ramakhrishna Velamuri, "The design of the member review: showing what to organization members and why", Organizational Research Methods, 12, 2009, pp. 488-509.

[30] A. Majchrzak, R.E. Rice, A. Malhotra, N. King, and S.L. Ba, "Technology adaptation: the case of a computersupported inter-organizational virtual team", MIS Quarterly, 24, 2000, pp. 569-600.

[31] A. Malhotra, and A. Majchrzak, "Enhancing performance of geographically distributed teams through targeted use of information and communication technologies”, Human Relations, 67, 2014, pp. 389-411.

[32] G. Mark, V.M. Gonzalez, and J. Harris, "No task left behind?: examining the nature of fragmented work", In Proceedings of the SIGCHI Conference on Human Factors in Computing Systems, ACM Press, New York, 2005, pp. 321330 .

[33] McKinsey and Company. Technology, jobs, and the future of work. A McKinsey Global Institute briefing note. December 2016. Available at http://www.lecadredigital.fr/wp-

content/uploads/2017/01/Etude-McKinsey-sur-lavenir-delemploi.pdf

[34] D. Nicolini, "Practice theory, work, and organization: an introduction”, Oxford University Press, Oxford, 2013.

[35] S. Raisch, J. Birkinshaw, G. Probst, and M.L. Tushman, "Organizational ambidexterity: balancing exploitation and exploration for sustained performance", Organization Science, 20, 2009, pp. 685-695.

[36] J. Rennecker, and L. Godwin, "Delays and interruptions: a self-perpetuating paradox of communication technology use", Information and Organization, 15, 2005, pp. 247-266.
[37] M. Robinson, M. Kovalainen, and E. Auramäki, "Diary as dialogue in papermill process control", Communications of the ACM, 43, 2000, pp. 65-70.

[38] B. Schreurs, and M. De Laat, "The network awareness tool: a web 2.0 tool to visualize informal networked learning in organizations", Computers in Human Behavior, 37, 2014, pp. 385-394.

[39] G. Schreyögg, and J. Sydow, "Crossroads - organizing for fluidity? Dilemmas of new organizational forms", Organization Science, 21, 2010, pp. 1251-1262.

[40] R.E. Stake, "Qualitative case studies", In the SAGE Handbook of Qualitative Research, 3rd edition, N.K. Denzin, and Y.S. Lincoln, eds., SAGE Publications, Thousand Oaks, CA, 2005, pp. 443-466.

[41] S.L. Star, and A. Strauss, "Layers of silence, arenas of voice: the ecology of visible and invisible work", Computer Supported Cooperative Work, 8, 1999, pp. 9-30.

[42] L. Suchman, "Making work visible", Communications of the ACM, 38, 1995, pp. 56-64.

[43] L. Suchman, "Human-machine reconfigurations: plans and situated actions", Cambridge University Press, New York, 2007.

[44] R. Susskind, and D. Susskind, "The future of the professions: how technology will transform the work of human experts", Oxford University Press, Oxford, 2015.

[45] J.B. Thompson, "The new visibility", Theory, Culture \& Society, 22, 2005, pp. 31-51.

[46] J.W. Treem, and P.M. Leonardi, "Social media use in organizations: exploring the affordances of visibility, editability, persistence, and association", Communication Yearbook, 36, 2012, pp. 143-189.

[47] C. Urquhart, H. Lehmann, and M.D. Myers, "Putting the 'theory' back into grounded theory: guidelines for grounded theory studies in information systems", Information Systems Journal, 20, 2010, pp. 357-381.

[48] C. Urquhart, and W. Fernández, "Using grounded theory method in information systems: the researcher as blank slate and other myths", Journal of Information Technology, 28, 2013, pp. 224-236.

[49] R.K. Yin, "Case study research", SAGE Publications, Thousand Oaks, CA, 2014.

[50] Y. Yoo, R. Boland Jr., and K. Lyytinen, "From organization design to organization designing", Organization Science, 17, 2006, pp. 215-229. 